\title{
Traumatic Occipital-Cervical Dislocation in Children and Adolescents: Two Years Follow-up Case Report and Review of the Literature
}

\section{Pawel Grabala*}

Regional Specialized Children's Hospital, Department of Pediatric Orthopaedic, Zolnierska 18A, 10-561 Olsztyn, Poland

\begin{abstract}
Background: Traumatic occipital-cervical dislocation (OCD) in children and adolescents is a rare and serious injury, which generally leads to death. For those who survive, there are usually severe and permanent neurological deficits.

Purpose: The purpose of this study is to present the case of a 13-year-old boy with OCD, the treatment and results at two years follow-up.

Study design/setting: The study design includes a case report and review of the literature.

Methods: We present a case of OCD survivor, two years of follow-up care, and review of the literature regarding OCD.

Results: A 13-year-old boy was injured in a car accident in 2013. He was admitted to the emergency department with OCD and multiple trauma. After vital signs were stabilized, occipital-cervical spinal fusion was performed. He was discharged home four months after the injury in good general condition, with neurological deficits resulting from the head and spinal cord damage.
\end{abstract}

Conclusions: $O C D$ in children and adolescents is quite rare and usually fatal. In spite of appropriate treatment (occipital-cervical fusion), the prognosis remains uncertain and at times poor due to irreversible neurological damage. Only a correct prompt diagnosis, along with immediate treatment initiation leads to survival.

\section{Introduction}

Injures of the cervical spine in children and adolescents are relatively rare and quite different from adults [1,2]. It was estimated that in the United States of America (USA) $1-10 \%$ of total annual spinal injuries were cases of pediatric spinal traumas [1]. Traumatic occipital-cervical dislocation (OCD) in children and adolescents is a rare and serious injury, which is usually as fatal in children as in adults. The exact incidence is unknown due to the very high mortality rate during the accident, but it is estimated that OCD constitutes $0.7 \%$ to $1.3 \%$ of all the cervical spine injuries [3,4]. It is usually caused by a high-energy trauma, such as a traffic accident. In recent years, there has been an increase in OCD due to the rapid development of motorization. Most cases of the OCD survivors had been reported in the last decade [5-10], due to the progress in cardiopulmonary resuscitation (CPR) techniques, modern equipment, faster diagnosis, and emergency treatment; however, survival rate is low and survivors usually have severe and permanent neurological deficits.

Because of the lack of information about long-term outcome of OCD survivors, here we present the case of 13 years old boy who survived traumatic OCD, information on surgical intervention, two years of follow-up care and early outcomes.

\section{Case Report}

A 13-year-old boy was admitted to the emergency department of our hospital (pediatric) with multiple trauma from a traffic accident in 2013. He was brought by an ambulance and without intubation, as he was breathing on his own. At admission, his Glasgow Coma Scale score was 8 and he was in a critical condition.

Computerized tomography (CT) scan and magnetic resonance imaging (MRI) revealed presence of blood in the subarachnoid areas of cerebral hemispheres, the ventricular system, the tentorium of the cerebellum, and the posterior cranial cavity. The brainstem and medulla oblongata displayed hematoma. There was massive contusion of the spinal cord at the $\mathrm{C} 1$ and $\mathrm{C} 2$ level; a congenital disconnection of the posterior vertebral arch at $\mathrm{C} 1$ and $\mathrm{C} 4$ level; dislocation of the right atlanto-occipital joint; subluxation of the left atlanto-occipital joint and subluxation on the right side at the $\mathrm{C} 1$ and $\mathrm{C} 2$ level (Figures 1-3). Furthermore, there was lung contusion, hemorrhagic pleural effusion, a large pulmonary hematoma in the omental sac, a large amount of blood between the intestinal loops, rupture of the small intestine and intestinal mesentery, several ruptures of the serous membrane of the small intestine, and contusion of the root of the intestinal mesentery.

Our initial management of OCD consisted of halo immobilization without traction.

Following stabilization of the vital signs and laparotomy, occipitalcervical fusion was performed (Figures 4-6) thereafter; the patient was transferred to an intensive care unit (ICU).

After initial emergency treatment, the patient remained verbally responsive. Six weeks after the accident, he was transferred from the ICU to the Department of Neurological Rehabilitation, to be rehabilitated. The rehabilitation period was complicated by thrombosis of the inferior vena cava and pneumonia.

Throughout postoperative care and rehabilitation, the patient was unable to talk and carried out breathing through a tracheotomy tube. Quadriplegia was noted (with more severe weakness of the left side), as were multiple joint flexion contractures, hollow feet, and flexion contractures of the toes. The patients' swallowing reflex was normal

*Corresponding author: Pawel Grabala, Regional Specialized Children's Hospital, Department of Pediatric Orthopaedic, Zolnierska 18A, 10-561 Olsztyn Poland, Tel: +48787111100; Fax: +48 775466324; E-mail: pgrabala@wp.pl

Received September 17, 2015; Accepted January 21, 2016; Published January 23, 2016

Citation: Grabala P (2016) Traumatic Occipital-Cervical Dislocation in Children and Adolescents: Two Years Follow-up Case Report and Review of the Literature. J Spine 5: 281.doi:10.4172/2165-7939.1000281

Copyright: ( $) 2016$ Grabala P. This is an open-access article distributed under the terms of the Creative Commons Attribution License, which permits unrestricted use, distribution, and reproduction in any medium, provided the original author and source are credited. 


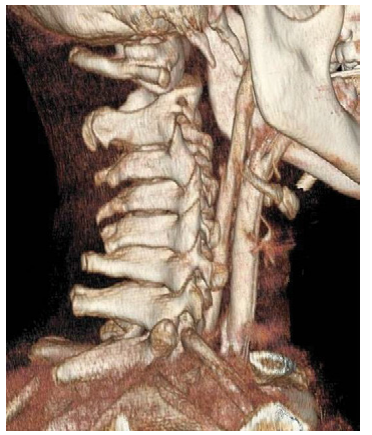

Figure 1: CT 3D image reconstruction, prior to the surgical procedure. Dislocation of the right atlanto-occipital joint, subluxation of the left atlantooccipital joint and subluxation on the right side at the $\mathrm{C} 1-\mathrm{C} 2$ level.

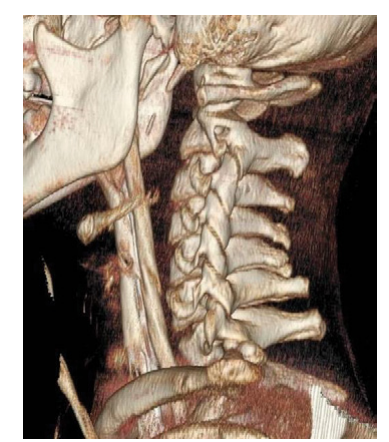

Figure 2: CT 3D image reconstruction, prior to the surgical procedure. Dislocation of the right atlanto-occipital joint, subluxation of the left atlantooccipital joint and subluxation on the right side at the C1-C2 level.

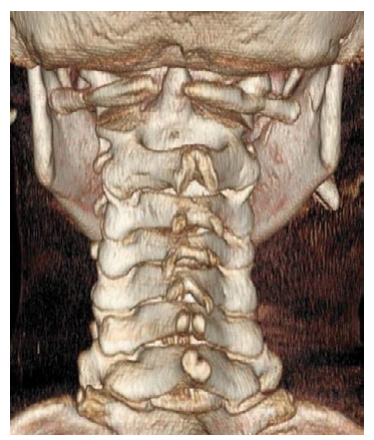

Figure 3: CT 3D image reconstruction, prior to the surgical procedure. Dislocation of the right atlanto-occipital joint, subluxation of the left atlantooccipital joint and subluxation on the right side at the C1-C2 level.

and he was fed orally. Due to patients' inability to stand, he was taught to use a wheelchair. Four months after the injury he was discharged home in good general condition with recommendations to continue pharmacological treatment and further rehabilitation.

At one-year follow-up, patients' condition had not changed significantly; he remained quadriplegic with severe brain injuries. Quadriplegia with more severe weakness of the left side, multiple joint flexion contractures, hollow feet, and flexion contractures of the toes persisted, and patient was wheelchair dependent. He had a tracheostomy, no functional use of his hands and received oral feeding. Brain injury had resulted in aphasia although he understood what was said to him. At present, at two years follow-up, his condition had improved slightly. He remained quadriplegic with severe brain injuries and presented with more severe weakness of the left side. He had continued pharmacological treatment and rehabilitation; however, multiple joint flexion contractures, hollow feet, and flexion contractures of the toes persisted. He did not have a tracheostomy, made sounds that were not words; however, he understood what was said to him. His hands lacked function and he was wheelchair dependent.

\section{Discussion}

Cervical spine injures are significantly different in children, adolescents and in adults, due to variations in anatomy and biomechanics of the spine. OCD is associated with severe damage to the ligaments, and generally results in death at the scene. The occipitalcervical passage largely comprises of ligamentous support structures, and there is almost no function of bones and joints. Ligaments are more flexible in childhood, and occipital condyles are sharper cup type, therefore, the risk of injury is higher [2].

When assessing the cervical spine injuries, given the developmental differences in the pediatric population they should be divided into two groups: younger children - up to nine years of age and older children - over nine years of age [11-13]. Injuries in children and adolescents under the age of two years are extremely rare and are recognized as cases of shaken baby syndrome [13-15]. Younger children mainly suffer from damage of the upper cervical spine, i.e. the occipital-cervical part up to the $\mathrm{Cl}$ and $\mathrm{C} 2$ level [13]. These children are also more likely to sustain ligament injuries, leading to instability at that level and neurological disorders, more often than fractures [11,15]. In older

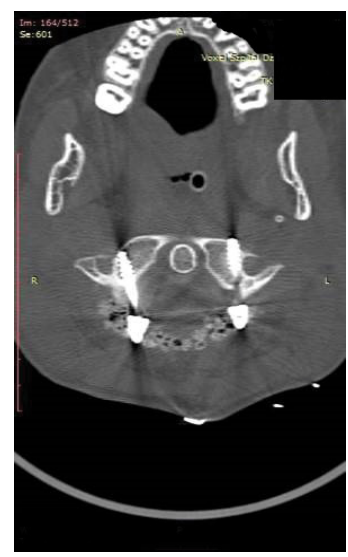

Figure 4: CT image after surgery (occipital-cervical fusion).

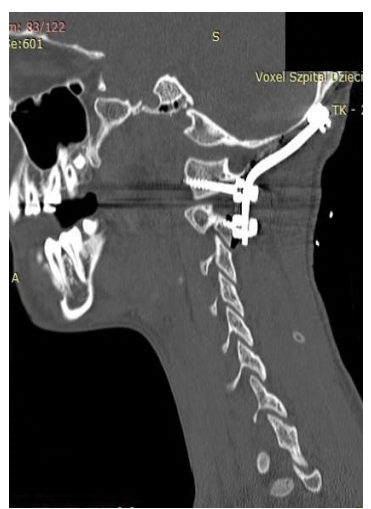

Figure 5: CT image after surgery (occipital-cervical fusion). 


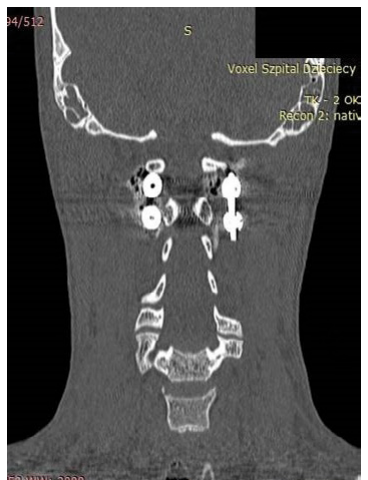

Figure 6: CT image after surgery (occipital-cervical fusion).

children, the cervical spine anatomy is somewhat similar to adults, therefore, injuries are similar to those in adults, and usually involve the lower cervical spine $[11,13]$.

Accident survivors can demonstrate serious and permanent neurological injuries usually resulting from the head and/or spinal cord damage [16]. At times, there are partial deficits of the cranial nerves and quadriplegia, while in other cases patients experience complete loss of the brain stem function, a vascular injury mainly at the level of the vertebral artery, the carotid artery, or the spinal cord at the C4 level, leading to suffocation [4,5]. A proper and prompt diagnosis prevents the occurrence or progression of neurological deficits and gives a much better prognosis in children than in adults $[11,17]$. The level of injury correlates with the age of the patient; younger children (age $<8$ years) tend to incur injures to the upper cervical spine, while older children and adolescents tend to incur injures throughout the cervical spine [14,18-20].

Modern management and CPR techniques have increased the survival rate in trauma patients. Intubation, however, is controversial as it is a high risk factor, which is a paradox: it either kills or saves life. In individuals with an unstable cervical spine, concern exists as manipulation during direct laryngoscopy to establish an airway may injure the spinal cord. During direct laryngoscopy, the cervical spine often is hyperextended to enable visualization of the glottis [21]. To increase the chances of survival in patients with OCD, we should suspect OCD in any traffic accident victim with a cervical spine injury. The clinical safety of orotracheal intubation with manual inline stabilization in individuals with unstable cervical spine fractures has been reported in other studies and various methods have been developed to diagnose OCD $[21,22]$.

In case of OCD, a quick and accurate diagnosis is very important, and CT scan and MRI can provide it [13-16]. Clinical symptoms as such are not definite, and are mainly neurological or cardiovascular. The clinical neurological symptoms may vary from neurological deficits and do not necessarily include quadriplegia $[11,17,23]$. Early diagnosis may be difficult due to spontaneous reduction after immobilization, and up to $60 \%$ of these injures may be missed [18-22]. A high index of suspicion should be maintained in the patients with closed head injury of significant facial trauma [18]. In severe cases, OCD is apparent on normal X-rays; however, the radiological assessment may sometimes appear normal. As OCD is a high-energy trauma, an appropriate diagnosis should be based on a CT scan and MRI.

Initial management of OCD consists of halo immobilization without traction or the Minerva casting. Definitive management with external immobilization should be used cautiously as there have been reports of late instability with halo immobilization and the Minerva casting $[18,24]$. Most of these injures ultimately require fusion due to loss of stability associated with the soft-tissue injury [18]. Axial traction has been proposed as an alternative form of immobilization of the cervical spine before surgery [24].

We believe the only appropriate treatment is direct immobilization (halo) and urgent occipital-cervical fusion (C0-C2), which allows preservation of the nervous system structures [25]. Unstable dislocations should always be treated through surgery as soon as possible [9,25-28]. Spinal fusion in children and adolescents with anatomic alignment and normal growth can be obtained with posterior as well as anterior approaches [29,30]. Our center prefers and recommends simultaneous surgery if possible. Fast repositioning, reduction, and stabilization promote healing and allow immediate rehabilitation.

\section{Conclusions}

The recovery prognosis in patients with OCD is uncertain and rather poor, however, that does not mean that these patients should not be treated. The development of medicine, medical interventions, and spinal surgery had certainly improved the survival rate. With the improvement in the performance of emergency departments, surgical techniques and experience of neurosurgeons, we can expect better outcomes in this respect. Skills and decisions at every level of treatment are important in such cases. Advanced imaging including CT scan and MRI assist with diagnosis and allow use of appropriate treatment. We should suspect OCD in each child presenting with a cervical spine injury, even in the absence of clinical symptoms. Only a correct and prompt diagnosis can improve the chances of survival. The surgical procedure itself is extremely difficult and carries the risk of iatrogenic complications. The aim should be to transfer the patient to a wellequipped center with skilled surgical specialists as soon as possible.

\section{References}

1. Greggi T, Scarale A, Maredi E, Lolli F, Martikos K, et al. (2015) The Cervica trauma in children: difficulties in diagnosis and treatment choice. J Spine 4: 214

2. Onen MR, Naderi S (2015) Pediatric spine trauma. J Spine 4: 211.

3. Labler L, Eid K, Platz A, Trentz O, Kossmann T (2004) Atlanto-occipital dislocation: four case reports of survival in adults and review of the literature. Eur Spine J 13: 172-180.

4. Bucholz RW, Burkhead WZ (1979) The pathological anatomy of fatal atlantooccipital dislocations. J Bone Joint Surg Am 61: 248-250.

5. Bools JC, Rose BS (1986) Traumatic atlantooccipital dislocation: two cases with survival. AJNR Am J Neuroradiol 7: 901-904.

6. Lee C, Woodring JH, Goldstein SJ, Daniel TL, Young AB, et al. (1987) Evaluation of traumatic atlantooccipital dislocations. AJNR Am J Neuroradiol 8: 19-26.

7. Levine AM, Edwards CC (1989) Traumatic lesions of the occipitoatlantoaxial complex. Clin Orthop Relat Res : 53-68.

8. Papadopoulos SM, Dickman CA, Sonntag VK, Rekate HL, Spetzler RF (1991) Traumatic atlantooccipital dislocation with survival. Neurosurgery 28: 574-579.

9. Traynelis VC, Marano GD, Dunker RO, Kaufman HH (1986) Traumatic atlantooccipital dislocation. Case report. J Neurosurg 65: 863-870.

10. Watridge CB, Orrison WW, Arnold H, Woods GA (1985) Lateral atlantooccipita dislocation: case report. Neurosurgery 17: 345-347.

11. Eleraky MA, Theodore N, Adams M, Rekate HL, Sonntag VK (2000) Pediatric cervical spine injuries: report of 102 cases and review of the literature. J Neurosurg 92: 12-17.

12. Lustrin ES, Karakas SP, Ortiz AO, Cinnamon J, Castillo M, et al. (2003) Pediatric cervical spine: Normal anatomy, variants, and trauma. Radiographics 23: 539-560.

13. Viccellio P, Simon H, Pressman BD, Shah MN, Mower WR, et al. (2001) A prospective multicenter study of cervical spine injury in children. Pediatrics 108 E20. 
Citation: Grabala P (2016) Traumatic Occipital-Cervical Dislocation in Children and Adolescents: Two Years Follow-up Case Report and Review of the Literature. J Spine 5: 281.doi:10.4172/2165-7939.1000281

14. Brown RL, Brunn MA, Garcia VF (2001) Cervical spine injuries in children: a review of 103 patients treated consecutively at a level 1 pediatric trauma center. J Pediatr Surg 36: 1107-1114.

15. Patel JC, Tepas JJ 3rd, Mollitt DL, Pieper P (2001) Pediatric cervical spine injuries: defining the disease. J Pediatr Surg 36: 373-376.

16. Adams VI (1992) Neck injuries: I. Occipitoatlantal dislocation--a pathologic study of twelve traffic fatalities. J Forensic Sci 37: 556-564.

17. Przybylski GJ, Clyde BL, Fitz CR (1996) Craniocervical junction subarachnoid hemorrhage associated with atlanto-occipital dislocation. Spine (Phila Pa 1976) 21: $1761-1768$

18. Jones TM, Anderson PA, Noonan KJ (2011) Pediatric cervical spine trauma. J Am Acad Orthop Surg 19: 600-611.

19. Osenbach RK, Menezes AH (1992) Pediatric spinal cord and vertebral column injury. Neurosurgery 30: 385-390.

20. Nitecki S, Moir CR (1994) Predictive factors of the outcome of traumatic cervical spine fracture in children. J Pediatr Surg 29: 1409-1411.

21. Vanderhave KL, Chiravuri S, Caird MS, Farley FA, Graziano GP, et al. (2011) Cervical spine trauma in children and adults: perioperative considerations. J Am Acad Orthop Surg 19: 319-327.

22. Sun PP, Poffenbarger GJ, Durham S, Zimmerman RA (2000) Spectrum of occipitoatlantoaxial injury in young children. J Neurosurg 93: 28-39.
23. Fruin AH, Pirotte TP (1977) Traumatic atlantooccipital dislocation. Case report. J Neurosurg 46: 663-666.

24. Georgopoulos G, Pizzutillo PD, Lee MS (1987) Occipito-atlantal instability in children. A report of five cases and review of the literature. J Bone Joint Surg Am 69: 429-436.

25. Pang D, Li V (2005) Atlantoaxial rotatory fixation: part 3-a prospective study of the clinical manifestation, diagnosis, management, and outcome of children with alantoaxial rotatory fixation. Neurosurgery 57: 954-972.

26. Houle P, McDonnell DE, Vender J (2001) Traumatic atlanto-occipital dislocation in children. Pediatr Neurosurg 34: 193-197.

27. Harris JH Jr, Carson GC, Wagner LK, Kerr N (1994) Radiologic diagnosis of traumatic occipitovertebral dissociation: 2. Comparison of three methods of detecting occipitovertebral relationships on lateral radiographs of supine subjects. AJR Am J Roentgenol 162: 887-892.

28. Herring JA (2001) Spinal injuries. Tachdjian's Pediatric Orthopaedics: from the Texas Scottish Rite Hospital for Children (3rdedn), Philadelphia: WB Saunders, 2091-2092.

29. McGrory BJ, Klassen RA (1994) Arthrodesis of the cervical spine for fractures and dislocations in children and adolescents. A long-term follow-up study. $J$ Bone Joint Surg Am 76: 1606-1616.

30. Hedequist D, Hresko T, Proctor M (2008) Modern cervical spine instrumentation in children. Spine (Phila Pa 1976) 33: 379-383. 